\title{
Modelo operário e percepção de riscos ocupacionais e ambientais: o uso exemplar de estudo descritivo*
}

\section{The "worker model" and perception of environmental and occupational risks: the optimal use of a descriptive study}

\author{
Luiz A. Facchini ${ }^{\star *}$, Elisabete Weiderpass ${ }^{\star *}$, Elaine Tomasi ${ }^{* \star}$
}

\begin{abstract}
FACCHINI, L.A. et al. Modelo operário e percepção de riscos ocupacionais e ambientais: o uso exemplar de um estudo descritivo. Rev. Saúde públ., S. Paulo, 25: 394-400,1991. Objetivou-se identificar os riscos resultantes da exposição a produtos químicos, de trabalhadores de indústria química e farmacêutica. Realizou-se estudo descritivo, através do modelo operário (MO), onde o acesso aos trabalhadores significava uma parte essencial do método e a única forma de neutralizar a impossibilidade de acesso ao local de trabalho. Reconstruíam-se as atividades dos setores de trabalho e identificaram-se as principais substâncias químicas utilizadas, as queixas mais referidas, os danos potenciais e os principais riscos ambientais, concluindo pela precariedade das condições gerais de trabalho. Com os resultados confirmados, ficou evidenciada a importância do $\mathrm{MO}$ e sua utilidade metodológica, levando trabalhadores a conseguir das autoridades que a empresa fosse vistoriada. A mobilização dos trabalhadores, através de denúncias nos meios de comunicação, ajudou a formar uma consciência popular dos riscos ocupacionais e ambientais daquela atividade produtiva.
\end{abstract}

Descritores: Riscos ocupacionais. Substâncias químicas, efeitos adversos. Exposição ocupacional.

\section{Introdução}

No Brasil, as condições de trabalho e os riscos a que estão expostos os operários dos diversos ramos produtivos ainda são tratados pelos patrões e pelo próprio Estado como segredo empresarial. Muitas vezes, as reivindicações relacionadas com a segurança no trabalho são punidas com a demissão pura e simples de trabalhadores, sem que se tenha mecanismos eficientes de contraposição a tais desmandos.

A dificuldade de acesso aos locais de trabalho, anteposta pela legislação vigente e pelos capitalistas, impede a realização de estudos que evidenciem, em toda sua complexidade, como o trabalho afeta a saúde dos trabalhadores. Assim, procura-se impedir a denúncia das precárias condições de trabalho existentes no país e a luta operária em defesa da saúde.

Uma das armas mais importantes no combate a este tipo de violência e discriminação contra a saúde dos trabalhadores é o chamado "Modelo Operário ou Sindical". Este método foi formulado em seus elementos fundamentais pelos operários italianos, com assessoria técnica de médicos, engenheiros e outros profissionais, e publicado pela primeira vez em $1969^{3,8}$. O modelo possibilita aos trabalhadores, com auxílio de técnicos, a reconstrução

* Trabalho apresentado no I Congresso Brasileiro de Epidemiologia. Campinas, SP, 1990.

** Departamento de Medicina Social da Universidade Federal de Pelotas - Pelotas, RS - Brasil.

Separatas/Reprints: L.A. Facchini - Caixa Postal 464 96100 - Pelotas, RS - Brasil. de seus processos de trabalho, com a identificação dos riscos e dos danos a que estão expostos, sem a necessidade de entrar na empresa.

Em abril de 1989, um grupo de trabalhadores de uma indústria química de Pelotas, RS, que havia sido demitido por reivindicar melhores condições de higiene e segurança no trabalho, solicitaram auxílio no sentido de respaldar suas reivindicações trabalhistas, identificando os danos à saúde que as substâncias químicas a que estavam expostos poderiam causar. A preocupação maior desses trabalhadores relacionava-se tanto às precárias condições de trabalho e à falta crônica de equipamentos de proteção individual e coletivo a que estavam submetidos, como ao aparecimento de diversos problemas de saúde, agudos e crônicos, entre seus companheiros de trabalho.

Para atender à demanda dos trabalhadores, em tais circunstâncias, optou-se por realizar o presente estudo através do Modelo Operário (MO). Neste caso, o acesso aos trabalhadores significou não apenas uma parte essencial do método, mas também uma forma de neutralizar a impossibilidade de acesso ao local de trabalho.

Também em função do conflito aberto pela empresa contra os trabalhadores teve-se a oportunidade de verificar a riqueza do MO e sua utilidade metodológica, comparando nossos dados com aqueles levantados por duas vistorias realizadas na empresa. Uma, feita pelo Centro de Estudos de Toxicologia, sediado em Pelotas, e a outra, realizada pelo Departamento de Meio Ambiente da Secretaria Estadual de Saúde e Meio Ambiente do Rio Grande do Sul. 


\section{Metodologia do estudo}

\section{Caracterização geral do Modelo Operário}

O MO foi desenvolvido como um método de geração do conhecimento para a ação. Seu princípio fundamental é a transformação das condições de trabalho, com vistas ao bem-estar e à proteção da saúde dos trabalhadores. Para isso, baseia-se no conhecimento detalhado do processo de trabalho ${ }^{3}$.

$\mathrm{A}$ inovação introduzida pelo $\mathrm{MO}$, em relação às práticas tradicionais de investigação da saúde dos trabalhadores, está sintetizada em sua operacionalização - descrita mais adiante - e nos quatro conceitos básicos que a sustentam:

a) Valorização da experiência ou subjetividade operária - Ao estudar a relação trabalho-saúde, algumas concepções não levam em conta a experiência e opinião dos trabalhadores. Estes são considerados enquanto objeto de estudo, e os pesquisadores como sujeitos "neutros", equidistantes de pontos de vista conflitantes.

No Modelo utilizado, a experiência operária faz parte da essência do método. Valorizá-la significa ter acesso e possibilidade de sistematizar um saber não disponível em abordagens mais tradicionais, mesmo naquelas técnicamente mais sofisticadas.

b) Não delegação da produção do conhecimento - Como consequiência do conceito anterior, os trabalhadores são não só fonte de informação, mas também os próprios sujeitos da investigação. $O$ saber acadêmico acumulado também é utilizado, pois geralmente diferentes especialistas participam como assessores de estudos baseados nesta metodologia.

c) Levantamento das informaçoes por grupos homogêneos de trabalhadores - A sistematização da experiência dos trabalhadores ocorre através de uma entrevista, estruturada em grupos de riscos ocupacionais, que é preenchida coletivamente por um grupo homogêneo, isto é, um grupo que comparte condições de trabalho iguais. Portanto, a unidade de observação não é o indivíduo, como em muitas abordagens, mas o coletivo.

d) Validação consensual das informaçōes - No levantamento dos dados, só se registram aquelas observações que o grupo homogêneo em seu conjunto reconhece como corretas ou válidas. Desta maneira, os resultados levantados são validados consensualmente, controlando-se a variabilidade individual de opiniões.

Dependendo dos recursos técnicos, dos equipamentos disponíveis e do acesso ao local de trabalho, pode-se continuar o estudo através da quantificação dos riscos e danos revelados durante a entrevista coletiva. Neste caso, a experiência operária é fundamental para orientar o que medir, onde e quando.

A partir das informações coletadas na enquete coletiva, pode-se elaborar um mapa, que é a síntese do processo de trabalho com seus riscos ocupacionais, danos à saúde e medidas de proteção existentes e propostas. O mapa também é útil para priorizar reivindicações, orientar e acompanhar modificações de riscos e danos presentes nos locais de trabalho?.

A ordenação dos riscos do ambiente de trabalho é feita em quatro grupos:

Grupo 1. Riscos que estão presentes no ambiente dentro e fora do local de trabalho - temperatura, iluminação, ruído, umidade e ventilação;

Grupo 2. Riscos característicos do ambiente de trabalho - poeiras/pós, gases, vapores e fumaças;

Grupo 3. Riscos referentes à fadiga derivada do esforço físico - levantamento e transporte de peso excessivo, posição viciosa; e

Grupo 4. Riscos capazes de provocar stress ou tensão emocional - monotonia, ritmos excessivos, repetitividade, ansiedade e responsabilidade ${ }^{8}$.

\section{Aspectos operacionais de sua aplicação}

Dada a impossibilidade de acesso à indústria para quantificar os riscos e caracterizar o processo de trabalho, foram trabalhados apenas os aspectos qualitativos proporcionados pela experiência dos trabaIhadores que integraram o grupo homogêneo.

Em termos operacionais, constituiu-se um grupo homogêneo de 5 operários com experiência em praticamente todas as atividades da empresa, especialmente na Planta Química, onde ocorre a atividade central da indústria e é determinado o ritmo global do processo de trabalho. Esta experiência é fruto da rotatividade quase cotidiana dos trabalhadores em diferentes funções nos diversos setores, seja na substituição de faltosos ou na solidariedade com os companheiros na execução das tarefas.

Considera-se que tanto o número, como a situação de desemprego dos trabalhadores, ocorrida há menos de um mês da coleta de dados, não dão a este grupo um significado diferente daquele utilizado no modelo original. Ao contrário, marcam certas particularidades que se verificam em estudos feitos no âmbito da luta operária por saúde.

O levantamento dos dados foi feito em 8 semanas, com reuniões semanais de cerca de duas horas. Ao longo deste período, o grupo homogêneo manteve sua constituição inicial.

A sistematização das informações coletadas baseou-se como previsto no modelo original ${ }^{\sharp}$, em um questionário estruturado a partir dos elementos fundamentais do processo de trabalho e dos grupos de risco em cada setor, e foi preenchido coletivamente. Embora o modelo original não apresente uma proposta acabada de instrumento, define aspectos que devem ser avaliados pelo grupo. Por isso, conside- 
ra-se oportuna a utilização de um questionário estruturado, que operacionaliza uma concepção de processo de trabalho, permitindo o entendimento de suas características, dos riscos ocupacionais que produz e da morbidade referida pelos trabalhadores. Em outras palavras, as discussões e os registros em cada reunião não devem ser fruto de uma decisão momentânea. $\mathrm{O}$ instrumento utilizado orientava a captação destes dados, a partir de questões genéricas e abertas. Outros autores, utilizando instrumentos mais fechados e extensos, obtiveram maiores evidências da relação entre processo de trabalho, riscos ocupacionais e saúde ${ }^{4}$.

A partir de cada um dos produtos elaborados (6APA, ampicilina tri-hidrato, ampicilina anidra, ampicilina benzatina e ampicilina sódica) reconstruiram-se as atividades que se realizam nos setores de trabalho da empresa e identificaram-se as principais substâncias químicas com que entram em contato cotidianamente os trabalhadores, assim como os danos mais aparentes. Através da bibliografia, conseguiu-se individualizar os possíveis danos causados à saúde por estas substâncias. $\mathrm{O}$ objetivo do presente estudo não era estabelecer uma relação de causa-efeito para cada substância química, mas estimar o conjunto dos danos potenciais derivados desta exposição simultânea e variável.

Para a reconstrução do processo de trabalho, foram identificados em cada departamento de trabalho:

- o objeto de trabalho, a tecnologia, as substâncias químicas utilizadas e os tipos de atividades desenvolvidas;

- as características da organização e divisão do trabalho e das relações sociais de produção e

- os riscos e danos mais importantes, derivados da combinação dos elementos fundamentais do processo de trabalho.

\section{Caracterização geral da empresa}

A atividade principal da indústria estudada tem sido a produção de ampicilinas dos tipos benzatina, sódica, anidra e tri-hidrato. Como principais matérias primas tem utilizado penicilina $\mathrm{G}$ potássica e ácido 6-amino-penicilânico (6-APA). Na ocasião do estudo, a indústria empregava 65 trabalhadores.

Através da reconstrução do processo de trabalho obteve-se uma visão global das atividades nos diferentes setores da indústria (Tabela 1).

Em termos tecnológicos, a indústria pode ser classificada, em seu conjunto, como de tipo mecanizada. No entanto, pode-se diferenciar uma variedade de bases técnicas em seus diferentes setores de trabalho, que vão desde atividades de manufatura até semi-automatizadas. Estas últimas estão concentradas no setor denominado Planta Química, que determina a ordem, o tempo e o ritmo ao conjunto dos
Tabela 1. Quadro descritivo simplificado do processo de trabalho em uma indústria química de Pelotas-RS, 1989.

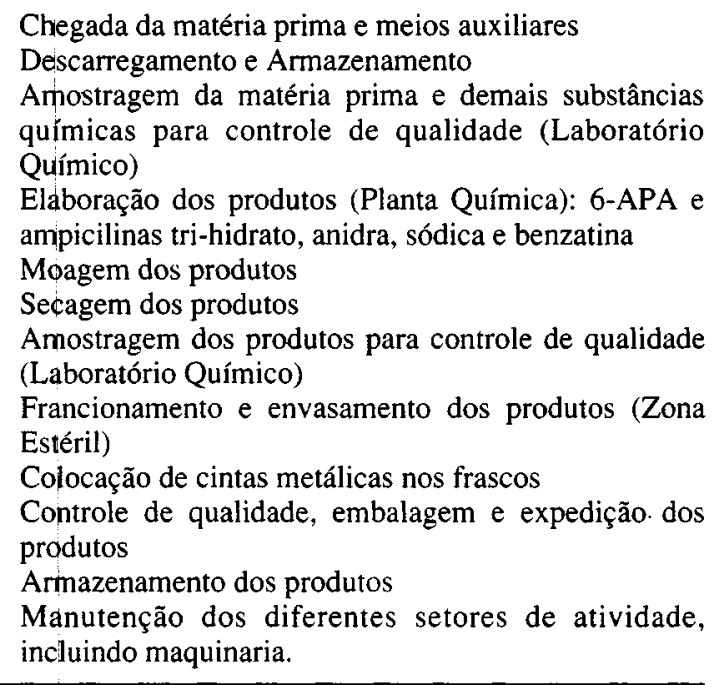

Tabela 2. Processo de produção de ampicilinas a partir da planta química de uma indústria química de PelotasRS, 1989.

Produto e passos subsequentes à planta química.

6-APA $\rightarrow$ secagem, se necessário $\rightarrow$ amostras para laboratório (controle de qualidade) $\rightarrow$ armazenamento do produto para uso na produção de ampicilina.

Ampicilina Tri-Hidrato $\rightarrow$ centrifugação $\rightarrow$ moagem, secagem $\rightarrow$ amostras para laboratório (controle de qualidade) $\rightarrow$ uma parte vai para fracionamento, embalagem e comercialização; e, outra parte é armazenada para uso interno na produção de ampicilina anidra.

Ampicilina Anidra $\rightarrow$ centrifugação; geralmente não é moída ou secada $\rightarrow$ amostras para laboratório (controle de qualidade) $\rightarrow$ fracionamento $\rightarrow$ embalagem $\rightarrow$ armazenamento para uso na produção de ampicilina sódica.

Ampicilina Sódica secagem $\rightarrow$ amostras para laboratório (controle de qualidade) $\rightarrow$ fracionamento $\rightarrow$ zona estéril: pura ou misturada com ampicilina benzatina $\rightarrow$ enfrascada, embalada, comercializada.

Ampicilina Benzatina $\rightarrow$ centrifugação $\rightarrow$ secagem $\rightarrow$ amostras para laboratório (controle de qualidade) $\rightarrow$ fracionamento/micronização $\rightarrow$ zona estéril $\rightarrow$ misturada com ampicilina sódica $\rightarrow$ enfrascada, embalada e comercializada.

setores e é o mais sofisticado no processo de trabalho estudado, sendo o local em que são elaborados os produtos finais (Tabela 2).

O salário médio na indústria correspondia a 1,17 salários mínimos ou cerca de 90 dólares, em maio 
de 1989 , havendo uma certa diferenciação salarial pela experiência na função ou antiguidade na empresa, mas inexistia um plano de carreira para o conjunto dos trabalhadores. Embora, desde 1987, todos os trabalhadores recebessem o adicional de insalubridade, nenhum deles receberá o adicional de periculosidade, mesmo tendo o direito assegurado pela legislação vigente.

O refeitório estava instalado sem condições de segurança e em área física precária, próximo aos tanques de acetona e de outras substâncias químicas.

\section{Aspectos da organização e divisão do trabalho}

- Em praticamente todos os setores da indústria (Tabela 1), com exceção da Planta Química, trabalhava-se 5 dias na semana, em 2 turnos diários de 8 horas. Nos fins de semana havia uma escala de plantões para vigilância da indústria e manutenção da maquinaria. A limpeza dos setores era feita pelos próprios operários da produção.

Na Planta Química, o regime de trabalho também era de 5 dias na semana, mas com 3 turnos diários e com revezamento semanal dos operários.

Em cada turno de trabalho havia um "líder", operário com funções de supervisor de produção, que fiscalizava e auxiliava os demais trabalhadores na execução de suas tarefas. Para o conjunto da produção havia um supervisor geral dos líderes, que coordenava o desenvolvimento do trabalho na indústria.

\section{Resultados e discussão}

O conhecimento das características gerais dos diferentes tipos de processo de trabalho é pouco difundido em nossa sociedade, estando concentrado entre especialistas mais relacionados com o mundo da produção, como, por exemplo, engenheiros e técnicos. $\mathrm{Na}$ área da saúde este conhecimento também é escasso, mesmo entre aqueles que estudam a problemática da interface entre trabalho e saúde. Nesta situação, a experiência operária foi duplamente importante. Primeiro, porque permitiu conhecer a generalidade dos processos químico-farmacêuticos e, em segundo lugar, porque evidenciou as particularidades do caso estudado.

Em relação a riscos e danos, há um acúmulo de informações acadêmicas que são úteis tanto para validar a subjetividade operária, como para dar perspectiva aos levantamentos transversais, incapazaes de captar problemas que só se manifestam após períodos longos de exposição.

Em função disso, na apresentação dos danos, completaram-se aqueles referidos pelos trabalhadores, em função da experiência no processo de traba-
Tabela 3. Substâncias químicas auxiliares identificadas na produção de ampicilinas em uma indústria química de Pelotas-RS, 1989.

\begin{tabular}{ll}
\hline Hidróxido de Amônia & Everbrit \\
Ácido Clorídrico & Citrato de Sódio \\
Cloreto de Cálcio & Formol \\
Hidróxido de Sódio & Áxido de Etileno \\
Dimetil Dicloro Silano & Cloreto de Metileno \\
Trimetil Cloro Silano & Tween 80 \\
Acetamida & Isopropanol \\
Cloridrato de Alfa Fenil Glicina & Acetona \\
Fenol & Trietil Amina \\
Acetato de Benzil Etileno Diamina & Acetato de Etila \\
Penta Cloreto de Fósforo & Metilato de Sódio \\
Nitrogênio & Ácido Fenil Acético \\
Polivinil Pirolidona &
\end{tabular}

lho, com informações disponíveis na literatura especializada ${ }^{5,69,11}$.

\section{Substâncias químicas identificadas}

A Tabela 3 mostra as substâncias químicas identificadas pelos operários na produção de ampicilina. Embora seja possível que alguns nomes não estivessem com a grafia correta, pela bibliografia pode-se identificar os grupos químicos e os efeitos potenciais sobre a saúde de cada uma das substâncias. A grande maioria delas tem efeitos deletérios à saúde amplamente descritos na literatura especializada $^{5,6,9,11}$. Cabe salientar a importância de possíveis sinergismos ou potencializações resultantes não só da exposição simultânea ao conjunto das substâncias, presentes constantemente no ambiente na forma de gases, vapores e poeiras, mas também da forma como o trabalho está organizado, implicando em altas temperaturas (no verão) e "stress" permanente, dentre outros aspectos.

\section{Riscos e danos à saúde}

A partir da reconstrução do processo de trabalho, sistematizaram-se os riscos e danos à saúde em cada setor e no conjunto da empresa. Entretanto, limitouse a descrevê-los apenas para a Planta Química e a empresa como um todo. Estas descrições permitiram ter uma idéia bastante precisa das condições de trabalho na indústria e de suas consequiências para a saúde dos trabalhadores.

Planta química . Na Planta Química são elaborados todos os produtos comercializados pela indústria (ampicilina tri-hidrato, ampicilina sódica, ampicilina anidra, ampicilina benzatina), além do ácido 6 amino penicilânico (6-APA), que é matéria prima para a produção de ampicilina tri-hidrato. 


\section{Grupos de riscos}

Grupo 1 - Riscos presentes no ambiente dentro e fora do local de trabalho.

- mudanças bruscas de temperaturas extremas;

- ruído intenso e contínuo.

Grupo 2 - Riscos característicos do ambiente de trabalho

- manuseio, sem proteção de substâncias químicas variadas, como por exemplo, penicilina $\mathrm{G}$ potássica, acetona, cloreto de cálcio, 6-APA, acetamida, cloreto de metileno, ampicilina tri-hidrato, ampicilina anidra e metilato de sódio;

- presença no ambiente de pó de penicilina, ampicilina anidra e metilato de sódio;

- presença de gases, vapores e odores irritantes e desagradáveis no ambiente, como por exemplo, cloreto de metileno, trietilamina, acetona, amoníaco, ácido clorídrico, isopropanol, acetato de etila.

Grupo 3 - Riscos referentes à fadiga derivada da atividade física.

- posições viciosas

Grupo 4 - Riscos capazes de provocar "stress" ou tensão emocional.

- antevisão do risco de intoxicação e acidentes;

- trabalho em turno rotatório e responsabilidade na elaboração dos produtos finais.

\section{Queixas referidas e danos mais prováveis}

ria

Queixas referidas:- alergia e irritação respirató-

- desenvolvimento de fungos nas mãos, fragilidade da pele, perda de unhas;

- irritação e queimaduras de pele, mucosa e outros tecidos corporais;

- embriguez, alteração comportamental, vertigem, náusea e vômitos;

- tremor, fraqueza, fadiga e depressão;

- cefaléia, nervosismo;

- resistência bacteriana a antibióticos;

- diminuição da capacidade auditiva;

- problemas músculo-esqueléticos.

\section{Danos mais prováveis ${ }^{5,69,11}$}

- lesão da mucosa bronquial, dispnéia e pneumonite;

- alteração do ritmo circadiano (ex.: insônia, problemas gastro-intestinais e sexuais);

- intoxicação aguda grave;

- intoxicação hepática;

- carcinogênese.

Empresa - Esta descrição sintetiza o conjunto dos riscos mais importantes a que estão submetidos os operários da indústria. Neste caso, registramos apenas os riscos comuns à totalidade dos departamentos que integram a indústria.

\section{Grupos de riscos}

Grupo 1 - Riscos presentes no ambiente dentro e fora do local de trabalho.

- mudanças bruscas de temperaturas extremas;

- ruído intenso e contínuo e

- altas temperaturas, especialmente no verão.

Grupo 2 - Riscos característicos do ambiente de trabalho

- manuseio, sem proteção, de substâncias químicas corrosivas e irritantes, como por exemplo, penicilina G potássica, acetona, cloreto de cálcio, 6 APA, acetamida, cloreto de metileno, ampicilina 3-hidrato, ampicilina anidra e metilato de sódio;

- presença no ambiente de pó de penicilina, ampicilina anidra e metilato de sódio e

- presença de gases, vapores e odores irritantes e desagradáveis no ambiente, como por exemplo, cloreto de metileno, trietilamina, acetona, amoníaco, ácido clorídrico, isopropanol e acetato de etila.

Grupo 3 - Riscos referentes à fadiga derivada da atividade

- posições viciosas.

Grupo 4 - Riscos capazes de provocar "stress" ou tensão emocional

- antevisão do risco de intoxicação e de acidentes graves;

- monotonia, repetitividade;

- trabalho em turno rotatório e

- responsabilidade na elaboração dos produtos finais.

\section{Queixas referidas e danos mais prováveis}

Queixas referidas: - alergia e irritação respiratória - desenvolvimento de fungos nas mãos, fragilidade da pele, perda de unhas;

- resistência bacteriana a antibióticos,

- irritação e queimaduras de pele, olhos, mucosa e outros tecidos corporais;

- vertigem, náusea e vômitos, tremor e fraqueza, tontura, desmaios e fadiga;

- cefaléia;

- problemas músculo-esqueléticos (lombalgia);

- sangramento nasal;

- problemas digestivos como gastrite e queimação no estômago e

- nervosismo, ansiedade, irritabilidade.

Danos mais prováveis $5.6,9.11$

- lesão da mucosa bronquial, dispnéia e pneumonite;

- intoxicação hepática, intoxicação aguda grave;

- carcinogênese;

- alteração do sistema nervoso central, alteração comportamental;

- hipoacusia;

- alteração do ritmo circadiano (ex.: insonia, problemas gastro-intestinais e sexuais);

- hemoptise. 


\section{Riscos de acidentes ambientais:}

Sistematicamente a indústria lança substâncias químicas não tratadas na rede de esgotos, como, por exemplo, mistura de água com ácido fenil acético e acetona.

Além disso, há riscos de explosão e incêndio devido a utilização de produtos altamente inflamáveis (acetona, trietilamina e isopropanol), a falta de equipamentos e infra-estrutura para prevenção e combate de incêndios, a inadequação e precária manutenção da área física da indústria para sua finalidade e a localização em zona residencial densamente povoada.

Comparação de dados: modelo operário e vistorias oficiais

Foram comparados os dados levantados pelo Modelo Operário (MO) e por vistorias realizadas na indútria pelo Departamento de Meio Ambiente da Secretaria Estadual de Saúde e Meio Ambiente (DMA-RS) e pelo Centro de Estudos de Toxicologia do Rio Grande do Sul (CET-RS). Em termos globais, destaca-se que, embora as vistorias tenham utilizado metodologia distinta daquela do MO, as conclusões foram semelhantes nos três levantamentos. Em relação ao tipo de atividade principal e o produto final, as más condições de armazenamento de substâncias químicas, os principais riscos ambientais, as precárias condições de instalação e a inadequada localização do prédio, a presença de odores, pós, gases e vapores de substâncias químicas no ambiente de trabalho e a falta de equipamentos de proteção individual, houve razoável concordância. Estes itens foram mais detalhados no MO.

Já as matérias primas principais, a inadequada disponibilidade e o precário funcionamento de equipamentos de proteção coletiva, os danos à saúde dos trabalhadores e o ruído ambiental foram registrados somente pelo MO e na vistoria do DMA-RS. Aqui também observou-se um maior detalhamento na informação proporcionada pelo MO.

Além disso, o regime de funcionamento da indústria, as substâncias químicas utilizadas na produção de ampicilinas, a manutenção e as más condições da maquinaria e instalações, as temperaturas extremas, a deficiente iluminação ambiental e a ineficiente atuação de orgãos de prevenção de acidentes e de higiene e segurança no trabalho foram coletados exclusivamente pelo MO. Dentre estes, destacam-se, por serem fatores importantes na determinação da morbidade, os riscos capazes de provocar "stress" ou tensão emocional (Grupo 4), $1,2,10$. Mais relacionados com a organização e divisão do processo de trabalho, os riscos do Grupo 4 são dificilmente captados em estudos tradicionais que, ao contrário do MO, não apresentam uma abordagem globalizadora de risco.
O fato de vistorias realizadas por instituições reconhecidas pelos próprios empresários terem descrito, através de observação direta, de maneira muito semelhante ao MO, características e riscos do processo de trabalho e danos prováveis à saúde dos trabalhadores, valida a metodologia deste modelo.

Por outro lado, a comparação ainda revela um maior detalhamento e riqueza qualitativa dos danos levantados pelo MO, o que parece dever-se a uma maior estruturação e sistematização dos elementos constitutivos do processo de trabalho e à valorização da experiência operária.

\section{Considerações Finais}

Considerou-se que um dos maiores méritos do Modelo Operário, em geral, e neste estudo, em particular, é revelar aquilo que as portas das fábricas tratam de tornar inviolável: as condições em que os trabalhadores produzem a riqueza social e têm suas vidas consumidas.

Ao abrir estas portas, o MO revela a intensidade da vida operária dentro da fábrica. Ao mesmo tempo em que produz mercadorias e se constitui como classe, o operariado desgasta-se de modo particular e muitas vezes assustador.

Para a classe trabalhadora, a oportunidade de lançar mão dessa metodologia na defesa de sua saúde é estratégica. Ao desvendar a intimidade secreta do processo de trabalho, recoloca a indústria como centro da vida social e não apenas como um "aparelho técnico de produção". Esta ação operária faz com que os locais de trabalho ressurjam como espaço de enfrentamento historicamente determinado entre classes, que em alguns casos chega a extrapolá-los e a invadir a cotidianeidade da populaçãa ${ }^{7}$.

O papel do MO no episódio relatado no presente estudo - demissão dos funcionários por reivindicação de melhores condições de trabalho - é exemplar. Mesmo demitidos, os trabalhadores se lançaram com determinação na luta em defesa de sua saúde. Participaram do presente estudo, dando concreção à metodologia proposta. De posse dos resultados pressionaram as autoridade municipais e estaduais. Conseguiu-se que a empresa fosse vistoriada por órgãos públicos e privados "isentos". Denunciaramse os achados da pesquisa e das vistorias nos meios de comunicação, tornando público os riscos que aquela atividade produtiva significava, não só para eles, mas especialmente para a população residente na região em que a empresa está instalada. Articularam-se com entidades da sociedade civil, principalmente ambientalistas, ajudando a formar uma consciência dos riscos ecológicos "patrocinados" pela empresa.

Durante este processo, a percepção popular do risco à saúde e ao ambiente determinado por aquela 
empresa disseminou-se pela cidade. Começou com os operários muito antes de serem demitidos. Extendeu-se aos moradores da vizinhança da empresa, que movem uma ação popular na justiça solicitando a proibição do funcionamento da empresa naquela zona da cidade, e alcançou o conjunto da opinião pública.

A principal limitação do modelo utilizado é de natureza analítica e prende-se à própria característica dos estudos descritivos, baseados em informaçōes qualitativas. Neste caso, somente instrumentos estruturados em uma perspectiva "matricial" conseguem realizar o cruzamento de algumas variáveis importantes em estudos desta natureza. De qualquer modo, acredita-se que o presente estudo cumpriu papel importante na luta operária por saúde e contribuiu para a melhoria da percepção coletiva de riscos ocupacionais e ambientais.

FACCHINI, L.A. et al. [The "worker model" and perception of environmental and occupational risks: the optimal use of a descriptive study]. Rev. Saúde públ., S. Paulo, 25: 394-400, 1991. An attempt was made to identify the risks resulting from exposure to the chemicals to which workers are exposed as well as from the poor working conditions to which they are subject in a chemical and pharmaceutical factory. A descriptive study based on the "workers model" - a methodological approach developed in Italy in the 60's, was carried out. Such a study requires direct contact with the workers and has the advantage of overcoming the difficulty of gaining access to their work-place. The activities of the different departments of the plant were reconstructed and the main chemicals used, the main physical complaints, the potencial harms and the main environmental risks identified. The report on the harmful working conditions produced was used by the workers as a means of pressing the authorities into carrying out an inspection of the plant concerned to verify its accuracy. The report's findings have been confirmed and demonstrate the usefulness of the methocological approach adopted. The workers' publicizing of the study's findings through the means of mass communication have helped to build up greater public awareness of the occupational and environmental risks of that particular industrial activity.

Keywords: Working risks. Hazandous substances, adverse effects. Occupational exposure.

\section{Roferencias Bibllograficas}

1. FRANKENHAUSER, M. \& GARDELL, B. Underload and overload in working life. J. hum. Stress, 2 (3): 35-46, 1976.

2. GARDELL, B. Scandinavian research on stress in working life. Int. J. Hith Serv., 12 (1): 31-42, 1982.

3. LAURELL, A.C. Ciencia y experiencia obrera. Cuad. pol., MExico, 41: 63-83, jul/dez. 1984.

4. LAURELL, A.C. et al. Manual: conocer para cambiar - Estudio de la salud en el trabajo. Mexico, Universidad Autonoma Metropolitana, 1989.

5. LEGATOR, M.S. et al., ed. The health detective's handbonk. Baltimore, Johns Hopkins University Preas, 1985.

6. MENDES, R. Medicima do trabalhm: doenças prafissionais. Sto Paulo, Sarvier, 1980.

7. MONTCOMERY, D. El control obrero en Estados Unidos: ensaios sobre la historia del trabajo. la lecnologia y las Iuchas obreras. Madrid, Ministerio Trabajo y Seguridad Social, 1985.

8. ODDONE, 1. et al. Ambiente de trabalho. Sio Paub, Hucitec, 1986.

9. RIBEIRO, H.P. \& LACAZ, F.C., org. De que adoecem e mor. rem os trabalhadores. S7o Paulo, DiesayMMESP, 1984.

10. RODRIGUEZ, C.A. et al. Proceso de trabajo y condiciones de salud de trabajadores expuestos a riesgo elsetrico. Rev. lationoamer. Salud, Mexico. 1: 41-72, 1981.

11. ROM, W., ed. Environmental and occupational medicine. Boston, Little, Brown \& Co., 1983.

Recebido para publicaçdo em 28/0I/1991. Reapresentado em 12/0711991. Aprovado para publicaçdo em 2410711991. 